\title{
Prevalence and associated economic loss of fetal wastage in small ruminants slaughtered at Addis Ababa municipality abattoir, Ethiopia
}

\author{
Befekadu Urga Wakayo ${ }^{1}$ and Yohanis Abrham ${ }^{2}$ \\ ${ }^{1}$ College of Veterinary Medicine, Jigjiga University, P.O. Box 1020, Jigjiga Ethiopia; Phone: +251- \\ 911731254 \\ ${ }^{2}$ College of Veterinary Medicine, Jimma University, P.O. Box 378, Jimma, Ethiopia
}

Corresponding Author; Dr. Befekadu Urga: Email: fikeurga@gmail.com

\begin{abstract}
The study examined prevalence and economic implications of abattoir pregnan$\mathrm{cy} /$ fetal wastage in small ruminants. Survey was conducted on ewes (n=201) and does $(\mathrm{n}=183)$ slaughtered at Addis Ababa municipality abattoirs, during December 2017 and January 2018. Female reproductive tracts were examined for presence and types of pregnancy and/ or gross disorders. Net economic loss and net economic risk due to abattoir fetal wastage were calculated for each species after accounting for naturally expected abortion and neonatal losses, and domestic net market values. One hundred forty-two (37\%) animals were pregnant $131(34.1 \%)$ with single and $11(2.9 \%)$ with twin fetus. A total of 153 fetuses were recovered giving a fetal wastage prevalence of $39.8 \%$. More animals in the second trimester $(25.5 \%)$ were slaughtered than those in first $(8.3 \%)$ or third $(3.1 \%)$ trimesters $(p<0.05)$. Prevalence of pregnancy was 32.8 $\%$ in does and $40.8 \%$ in ewes $(p=0.104)$. Prevalence of fetal wastage was 37.2 $\%$ (68 fetuses) and $42.3 \%$ (85 fetuses) in goats and sheep, respectively ( $p>$ $0.05)$. Abattoir pregnancy prevalence showed variations relative to slaughter month in goat $(p<0.01)$ and body condition in sheep $(p<0.05)$. Observed abattoir pregnancy prevalence levels incurred net economic loss of 313.55 USD in sheep (per 201 ewes) and 315.4 USD in goats (per 108 doe). This translated to net economic risk of 1.7 USD per mature doe or ewe slaughtered for meat. Nine $(4.9 \%)$ does and $1(0.5 \%)$ ewe showed gross reproductive tract disorders $(p<0.05)$. Frequent female slaughter without efficient ante-mortem pregnancy screening predisposed significant proportion of small ruminants to pregnancy/ fetal wastage. Deeper investigations are needed to understand reasons behind pregnant small ruminant slaughter and to mitigate its negative impacts on sustainability of animal production. Evaluating and capacity building on alternative small ruminant pregnancy diagnosis methods requires due attention.
\end{abstract}


Key words: Doe; Pregnancy; Reproductive disorders; Ewe; Fetal wastage; Economic implication; Abattoir

\section{Introduction}

Ethiopia owns 30.7 million sheep and 30.2 million goats (CSA, 2017). Small ruminants account for a quarter of domestic annual meat consumption as well as over $90 \%$ of live animals and meat exported annually from the country. However, national off-take rate, carcass yield and per-capita consumption for mutton $(33-40 \%, 10 \mathrm{~kg}$ and $1.3 \mathrm{~kg})$ and goat meat $(27-35 \%, 8 \mathrm{~kg}$ goat, and $1.3 \mathrm{~kg}$ ), respectively, are very low even by sub-Saharan Africa standards. In absence of tangible productivity gains, rapidly growing local demands for meat are driving sustained increase of annual small ruminant slaughter volumes in Ethiopia (Legese and Fadiga, 2014; Shapiro et al., 2017; Eshetie et al., 2018).

Across sub-Saharan Africa, similar pressure to meet rising human demand for meat has been linked to significant pregnant livestock slaughter and fetal wastage which seriously undermine sustainable animal protein production. In part, later trends reflected effects of farmers economic and husbandry limitations and weak slaughter regulation (Abassa, 1995; Tizhe et al., 2010; Fayemi and Muchenje, 2013). There are several methods of small ruminant pregnancy diagnosis with choices depending on gestation stages and level of expertise and technical inputs available. Real time ultrasonography is by far the most reliable method followed by plasma or milk progesterone analysis. More advanced accurate pregnancy detection methods are often used in modern small ruminant operations of developed regions but remain inaccessible in most tropic extensive farming systems (Noakes et al., 2001; Tamassia, 2007; Ptaszynska, 2009). Hence, unknowing farmer dispatch of pregnant stock to slaughter could be substantially lower in developed regions.

Considerable risk of small ruminant fetal wastage is highly likely in Ethiopian contexts. Annual domestic female small ruminant (mainly replacement stocks) slaughter shares increased from $26.6 \%$ (1.26 million) to $29.1 \%$ (1.92 million) in past decade alone (CSA, 2008; CSA, 2017). Ethiopia's Meat Inspection Regulation (Section 2 Article 10.3.) indicated recommends that pregnant animals should be withheld from slaughter at ante-mortem examination (MoA, 1993). Still, uncontrolled small ruminant breeding (Abebe, 2008) and slaughter (Legese and Fadiga, 2014; Mummad and Webb, 2015) systems typical across the 
country make it doubtful that females destined for meat undergo formidable pregnancy screening. Accordingly, high levels of abattoir pregnancy and fetal wastage were reported in sheep (> $70 \%)$ and goats $(47 \%)$ from the central highlands (Mukasa-Mugerwa and Tekelye, 2003; Tamirat et al., 2015). However, situation of small ruminant abattoir fetal wastage at Addis Ababa, probably the largest urban meat consumer market in Ethiopia, is unknown. Therefore, this study explored prevalence pregnancy/ fetal wastage and associated economic losses in doe and ewes slaughtered at Addis Ababa municipality abattoir. Further interest was on describing type and prevalence of gross female reproductive disorders.

\section{Materials and methods}

\section{Study area}

Addis Ababa is the capital and administrative center of Federal Democratic Republic of Ethiopia. The city is located on $9^{\circ} 1^{\prime} 48^{\prime} \mathrm{N}$ latitude, $38^{\circ} 44^{\prime} 24^{`} \mathrm{E}$ longitude and average altitude of 2,400 meters above sea level. Addis Ababa city has an estimated land cover of 530.14 square kilometers and population density of 5,165.1 inhabitants per square kilometer. It has a cool humid climate with bimodal annual rainfall averaging $1800 \mathrm{~mm}$ and average daily temperature ranging from 10.7 to $25.6^{\circ} \mathrm{C}$ (Beshada, 2012; Assefa et al., 2017).

\section{Study population}

The study population comprised of mature does and ewes slaughtered at Addis Ababa municipality abattoir. This facility is over 60 years old and was reported to slaughter 36,000 sheep and 18,000 goats in a year (Assefa et al., 2017). Recent slaughter statistics stratified by sex and age proved difficult to access. Slaughter animals are supplied to Addis Ababa city from different parts of Ethiopia including; Northwest, west, Northeast, east and south west in decreasing order of shares (Beshada, 2012). This represents diverse highland and lowland small ruminant production systems in the country.

\section{Study design and variables}

Cross-sectional abattoir survey was conducted to explore pregnancy, fetal wastage and gross reproductive disorders in mature does and ewes slaughtered at 
Addis Ababa municipality abattoir during December 2017 and January 2018. Outcomes of interest were abattoir pregnancy/ fetal wastage prevalence (number of pregnant females/ fetuses divided by total female examined x 100), and associated net economic losses (NEL) and net economic risks (NER) as well as prevalence (affected/ examined females x 100) and types of gross female reproductive disorders. The independent variables included animal species, body condition and study months.

\section{Sampling method and sample size}

Thirty abattoir survey dates were selected by random lottery method in December 2017 (16) and January 2018 (14). Abattoir was visited from 5 PM to 10 $\mathrm{PM}$ and all mature does and ewes slaughtered at this time were sampled. Sample size (n) was calculated using the formula by Thrusfield (2015) for simple random samples with $50 \%$ expected prevalence (Pexp), $5 \%$ desired precision level (d) and $95 \%$ confidence level $(\alpha=0.05)$. Accordingly, 384 study animals were sampled including 183 does and 201 ewes. Average daily frequency of study animals was 12 during December 2017 (6 doe and 6 ewes) and 14 in January 2018 (8 doe and 6 ewes).

\section{Abattoir study methods}

Ante-mortem examination of small ruminant at the study abattoir was limited to inspection for physical problems and no reliable pregnancy screening system was in place. On slaughter floor, female small ruminants were checked for maturity based on presence of more than 2 pairs of permanent incisors. Body condition of study animals was subjectively classified as thin, medium and fat according to ESGPIP (ESGPIP, Technical Bulletin No. 8). Post mortem, female reproductive tracts were harvested intact and examined by inspection, palpation and uterine incision to detect pregnancy and/ or gross disorders (e.g. pyometra denotes uterine lumen distended with pus and imminent abortion referred to abnormal appearance of fetal fluids, fetus and placenta indicative of pregnancy disruption). In pregnant females, liter size was recorded and crown - rump length (CRL) of largest fetus was measured (cm) using measuring tape or ruler as previously described (Tamirat et al., 2015). Fetal age (FA) or gestation length (GL) was calculated (in days) from CRL measurement using recommended formulas (Sivachelvan et al., 1996; Hussein, 2008). Based on the estimated FA/ GL, stage of pregnancy was classified in to $1^{\text {st }}\left(<50\right.$ days), $2^{\text {nd }}$ (50 to 100 days) and $3^{\text {rd }}$ (> 100 days) trimester. 


$$
\begin{aligned}
& \text { Sheep GL/ FA (in days })=2.1(\mathrm{CRL}+17) \& \\
& \text { Goat GL/ FA (in days })=(2.74 \times \mathrm{CRL})+30.15
\end{aligned}
$$

In pregnant small ruminants, month of fertile mating was approximated by counting back GL/ FA days from date of abattoir detection. Corresponding parturition months were estimated by counting forward from abattoir detection date the difference between average small ruminant gestation length (150 days) and calculated GL/ FA (n days).

\section{Economic analysis}

Economic impact of fetal wastage reflects financial value of potential offspring's forgone due to slaughter of pregnant female animals for human meat consumption. This study drew on abattoir fetal wastage economic loss estimation methods that account for naturally expected abortion/ stillbirth and neonatal mortality losses described by other studies (Tamirat et al., 2015; Kashoma and Melkiory, 2017). The approach was modified by considering net market return values (gross value - rearing costs) of sheep and goats in Ethiopia so as to estimate net economic loss (NEL) due to pregnancy/ fetal wastage for total animals examined as outlined below.

NEL $($ Birr $)=$ NMRV $($ Birr/ Animal) $\mathrm{x}$ VOW (n Animals $)$ where;

NMRV stands for net market return value of sheep (223.0) and goats (267.3) in Ethiopia calculated by averaging values reported by Shapiro et al. (2017). VOW denotes net quantity of viable offspring's wasted due to observed abattoir pregnant slaughters. This was calculated by deducting naturally expected abortion/ stillbirth and neonatal mortality losses from observed abattoir pregnancy/ fetal wastage levels in each small ruminant species as outlined below.

VOW (n) = Live Born Offspring (n) - Premature Offspring Mortality (n)

Live born offspring $(\mathrm{n})=$ birth) X Average liter size (n)

(n) Pregnant females (Total- Abortion/ Still

Abortion/ Still birth $(\mathrm{n})=\quad$ Total pregnant females (n) X Expected abortion/ still birth prevalence (\%) 
Expected abortion/ still birth prevalence (ExpASbP) was approximated by averaging previous national estimates (Fentie et al., 2016) for goats $(16.8 \%)$ and sheep $(14.7 \%)$

Premature offspring mortality $(n)=\quad$ Live born offspring $(n)$ X Expected offspring mortality prevalence (\%)

Expected offspring mortality prevalence (ExpOMP) was approximated to 18.8 $\%$ for both goats and sheep by averaging national estimates reported by Fentie et al. (2016) and CSA (2017)

To appreciate current NEL projections on larger slaughter volumes, the study calculated net economic risk (NER) which reflects pregnancy/ fetal wastage related financial loss risk expected when 1 mature doe or ewe is slaughtered for human consumption. For each small ruminant species, NER (Birr or USD/ mature female slaughtered) was calculated by dividing NEL with total number of females examined (n).

\section{Data analysis}

Study months, animal species and body condition, gross reproductive disorder (presence and type) and pregnancy (presence, liter size and CRL (cm), FA/ GL (days), gestation stage) observations were recorded and/ or calculated on Microsoft Excel Sheet. Economic loss (Birr/USD) calculations were done on a separate Microsoft Excel sheet using built in arithmetic functions on combination of observed and referred input variables. Further statistical analysis was carried out on SPSS version 16 software. Categorical variables were summarized in frequency (n (\%)) tables and frequency distribution of fertile mating months was contrasted using line graphs with $95 \%$ confidence interval (CI). Numerical variables (CRL and FA/ GL) were summarized using mean \pm standard error. Association between categorical factors and outcomes was analyzed using Chi-square and Fisher exact tests. Relationship of numerical and categorical variables was evaluated by comparison of means using $95 \%$ confidence interval (CI). Statistical significance was set at $p<0.05$. 


\section{Results}

Pre-slaughter 17 (4.4\%), 170 (44.3\%) and 197 (51.3\%) animals exhibited thin, medium and good body conditions, respectively $(p<0.05)$. Post-mortem reproductive examination revealed that $142(37 \%)$ female small ruminants were pregnant with single $(34.1 \%)$ and twin $(2.9 \%)$ fetus $(p<0.05)$. A total of 153 fetuses were recovered giving an overall abattoir fetal wastage prevalence of $39.8 \%$. Prevalence of pregnant slaughter was $32.8 \%$ in does and $40.8 \%$ in ewes (Chi-square $=2.64, p=0.104)$. Twin pregnancy was higher (Chi-square $=4.54, p=0.033)$ in does $(4.4 \%)$ than in ewes $(1.5 \%)$. Overall prevalence of fetal wastage was $37.2 \%$ ( 68 fetuses) in goat and $42.3 \%$ ( 85 fetuses) in sheep $($ Chi-square $=1.53, p=0.216)$.

Fetal CRL and calculated FA/ GL varied widely amongst pregnant small ruminants but showed limited average variation in relation to animal species (Table 1). More pregnant small ruminants were in second trimester (25.5\%) compared to counterparts in first $(8.3 \%)$ and third $(3.1 \%)$ trimesters $(p<$ 0.05). Likewise, more fetuses were lost from second trimester pregnancy (27.1 $\%)$ than either first $(9.4 \%)$ or third $(3.4 \%)$ trimester pregnancies $(p<0.05)$. Prevalence patterns of pregnancy and fetal wastage at different trimesters were consistent in goats and sheep (Table 1)

Table 1. Fetal length, age, gestation stage in pregnant small ruminants slaughtered at Addis Ababa Municipal abattoir

\begin{tabular}{|c|c|c|c|c|}
\hline Variable & $\begin{array}{l}\text { Statistics/ } \\
\text { Categories }\end{array}$ & $\begin{array}{c}\text { Total } \\
(\mathrm{N}=140)\end{array}$ & $\begin{array}{c}\text { Goat } \\
(\mathrm{N}=60)\end{array}$ & $\begin{array}{l}\text { Sheep } \\
(\mathrm{N}=82)\end{array}$ \\
\hline \multirow{3}{*}{$\begin{array}{l}\text { CRL } \\
(\mathrm{cm})\end{array}$} & Min-Max & $3-35$ & $3-34$ & $4-35$ \\
\hline & Mean $\pm \mathrm{SE}$ & $15.34 \pm 0.70$ & $13.4 \pm 1.05$ & $16.75 \pm 0.91$ \\
\hline & 95 \% CI; LB-UB & $13.96-16.72$ & $11.29-15.51$ & $14.95-18.56$ \\
\hline \multirow{3}{*}{$\begin{array}{l}\text { FA / GL } \\
\text { (Days) }\end{array}$} & Min-Max & $42-109.2$ & $42-107.1$ & 44.1-109.2 \\
\hline & Mean $\pm \mathrm{SE}$ & $67.91 \pm 1.5$ & $63.8 \pm 2.21$ & $70.89 \pm 1.91$ \\
\hline & 95 \% CI; LB-UB & $65.01-70.81$ & $59.42-68.26$ & $67.09-74.68$ \\
\hline \multirow{3}{*}{$\begin{array}{l}\text { Pregnancy } \\
\text { n (\%) }\end{array}$} & $1^{\text {st }}$ Trimester & $32(8.3)$ & $17(9.3)^{\mathrm{b}}$ & $15(7.5)^{\mathrm{b}}$ \\
\hline & $2^{\text {nd }}$ Trimester & $98(25.5)$ & $39(21.3)^{\mathrm{a}}$ & $59(29.4)^{\mathrm{a}}$ \\
\hline & $3^{\text {rd }}$ Trimester & $12(3.1)$ & $4(2.2)^{c}$ & $8(4)^{c}$ \\
\hline \multirow{3}{*}{$\begin{array}{l}\text { Fetal Wastage } \\
\mathrm{n}(\%)\end{array}$} & $1^{\text {st }}$ Trimester & $36(9.4)$ & $20(10.9)^{b}$ & $16(8)^{b}$ \\
\hline & $2^{\text {nd }}$ Trimester & $104(27.1)$ & $44(24)^{\mathrm{a}}$ & $60(29.9)^{\mathrm{a}}$ \\
\hline & $3^{\text {rd }}$ Trimester & $13(3.4)$ & $4(2.2)^{\mathrm{c}}$ & $9(4.5)^{c}$ \\
\hline
\end{tabular}


Approximated fertile mating (conception) time of pregnant small ruminants was higher $(p<0.05)$ around October $(38.7 \%)$ and November $(38 \%)$ than in September $(6.5 \%)$ and December $(2.1 \%)$. Corresponding expected parturition (lambing/ kidding) dates concentrated $(p<0.05)$ during March $(46.5 \%)$ and April (34.5 \%) than in February (4.7\%) and May (2.3\%). Respective temporal reproductive variations were consistent in pregnant does and ewes (Figure 1 $a, b)$.
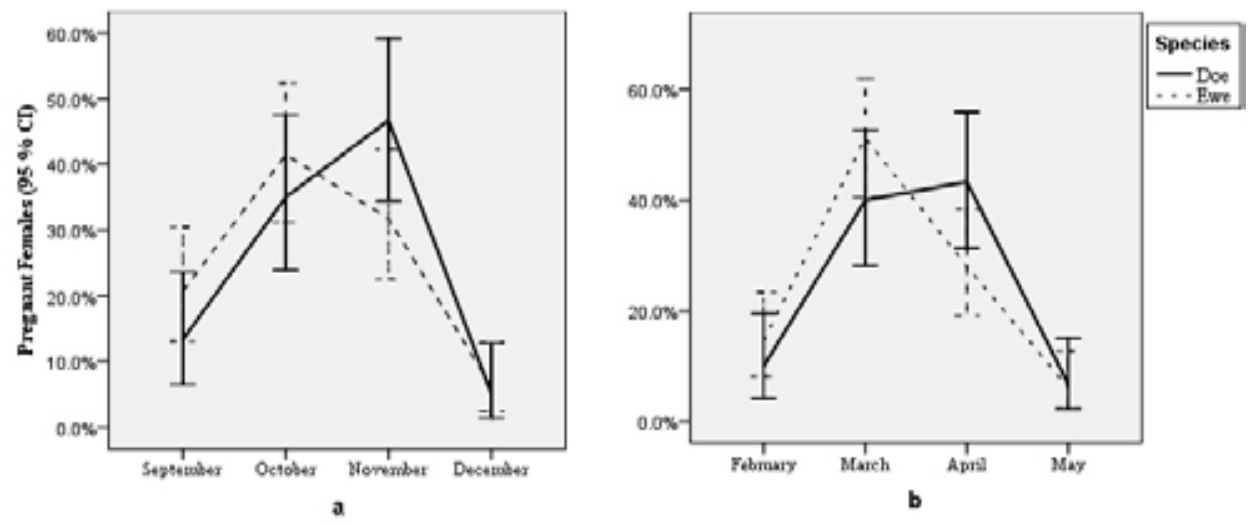

Figure 1. Fertile mating (a) and parturition (b) months relative to species of pregnant animals

On the other hand, 10 (2.6 \%) female small ruminants exhibited gross reproductive disorders including pyometra (1.6\%) and signs of abortion (hemorrhagic turbid fetal fluid and/ or placental lesions) in progress (1\%). A single case of pyometra was detected in ewes $(0.5 \%)$ whereas remaining disorders were observed in does i.e. pyometra (2.7\%) and abortion (2.2 \%). Total prevalence of reproductive disorders was higher in does $(4.9 \%)$ than in ewes $(0.5 \%)$ (Chi-square $=7.38, p=0.007)$.

Overall, prevalence of small ruminant pregnancy and fetal wastage (Chi square $=5.67, p=0.017$ ) were higher during January 2018 than December 2017 whereas gross reproductive disorders showed limited temporal variation. Body condition was not significantly associated to prevalence of pregnancy (Chi square $=3.77, p=0.104)$, fetal wastage (Chi square $=4.47, p=0.107)$ and reproductive disorders (Chi square $=2.9, p=0.235$ ). Species wise, association of study months to prevalence of pregnancy (Chi square $=12.4, p=0.000$ ) and fetal wastage (Chi square $=11.95, p=0.001)$ were significant in goats. In 
sheep, prevalence of pregnancy (Chi square $=8.4, p=0.015)$ and fetal wastage (Chi square $=8.3, p=0.016$ ) were higher in fat than thin body condition groups (Table 2).

Table 2. Association Prevalence of pregnancy, fetal wastage, and reproductive disorders with study month and body condition of slaughtered small ruminants

\begin{tabular}{|c|c|c|c|c|c|c|}
\hline Animals & Factors & Categories & $\begin{array}{l}\text { Examined } \\
(\mathrm{N})\end{array}$ & $\begin{array}{l}\text { Pregnant } \\
\text { N (\%) }\end{array}$ & $\begin{array}{l}\text { Fetal } \\
\text { Wastage } \\
\text { N (\%) }\end{array}$ & $\begin{array}{l}\text { Reproductive } \\
\text { Disorders N } \\
(\%)\end{array}$ \\
\hline \multirow{5}{*}{ Total } & \multirow[t]{2}{*}{ Study month } & Dec 2017 & 190 & $59(31.1)$ & $64(33.7)$ & $4(2.1)$ \\
\hline & & Jan 2018 & 194 & $83(42.8) *$ & $89(45.9) *$ & $6(3.1)$ \\
\hline & \multirow{3}{*}{$\begin{array}{l}\text { Animal Body } \\
\text { Condition }\end{array}$} & Thin & 17 & 3 (17.6) & 3 (17.6) & - \\
\hline & & Medium & 170 & $60(35.3)$ & $64(37.6)$ & $7(4.1)$ \\
\hline & & Fat & 197 & $79(40.1)$ & $86(43.7)$ & $3(1.5)$ \\
\hline \multirow{5}{*}{ Goats } & \multirow{2}{*}{$\begin{array}{l}\text { Study } \\
\text { Period }\end{array}$} & Dec 2017 & 101 & $22(21.8)$ & $26(25.7)$ & $4(4)$ \\
\hline & & Jan 2018 & 82 & $38(46.3)$ * & $42(51.2) *$ & $5(6.1)$ \\
\hline & \multirow{3}{*}{$\begin{array}{l}\text { Animal Body } \\
\text { Condition }\end{array}$} & Thin & - & - & - & - \\
\hline & & Medium & 77 & $27(35.1)$ & $29(37.7)$ & $6(7.8)$ \\
\hline & & Fat & 106 & $33(31.1)$ & $39(36.8)$ & $3(2.8)$ \\
\hline \multirow{5}{*}{ Sheep } & \multirow{2}{*}{$\begin{array}{l}\text { Study } \\
\text { Period }\end{array}$} & Dec 2017 & 89 & $37(41.6)$ & $38(42.7)$ & \\
\hline & & Jan 2018 & 112 & $45(40.2)$ & $47(42)$ & $1(0.9)$ \\
\hline & \multirow{3}{*}{$\begin{array}{l}\text { Animal Body } \\
\text { Condition }\end{array}$} & Thin & 17 & $3(17.6) \mathrm{b}$ & $3(17.6) b$ & \\
\hline & & Medium & 93 & $33(35.5)$ & 35 (37.6) & 1 )1.1) \\
\hline & & Fat & 91 & $46(50.5) \mathrm{a}$ & $47(51.6) \mathrm{a}$ & \\
\hline
\end{tabular}

Superscript ${ }^{*}$ and ${ }^{\mathrm{a} \& \mathrm{~b}}$ indicates variations of specific column variable in different categorical factor levels at $p<0.05$ level ( 2 sided)

After accounting for pregnancy and neonatal losses expected under local conditions, abattoir small ruminant pregnant slaughters incurred net loss of 105 viable offspring (59 sheep and 46 goats) per 384 mature females (201 ewes and 183 doe) slaughtered. This amounted to NEL of 25,415.7 birr (628.95 USD at December 122020 exchange rates of 1 USD $=38.82$ birr). Projected NEL estimates amounted to 12,243.6 birr (315.4 USD) in goats and 13,172.2 birr (313.55 USD) in sheep. These NEL estimates translate to NER of 66.9 birr (1.72 USD) and 65.5 (1.69 USD) per mature doe and ewe slaughtered at the abattoir, respectively (Table 3). 
Table 3. Abattoir pregnancy/ fetal wastage related economic impact calculations and estimates

\begin{tabular}{|c|c|c|c|}
\hline ID & Input Variables & Goats & Sheep \\
\hline A & Females Examined (n) & 183 & 201 \\
\hline B & Females Pregnant (n) & 60 & 82 \\
\hline $\mathrm{C}$ & $\begin{array}{l}\text { Total Fetus in Pregnant } \\
\text { Females (n) }\end{array}$ & 68 & 85 \\
\hline $\mathrm{D}$ & $\begin{array}{l}\text { Average Fetus per Pregnant } \\
\text { Females }(n)=\text { C/ B }\end{array}$ & 1.13 & 1.04 \\
\hline $\mathrm{E}$ & $\begin{array}{l}\text { Pregnant Females' Abortion-stillbirth } \\
\text { (n) } \\
=\text { ExpASbP (Fentie et al., 2016) } x B\end{array}$ & $\begin{array}{c}10 \\
(16.8 \% \mathrm{X} 60)\end{array}$ & $\begin{array}{c}12 \\
(14.7 \% \mathrm{x} 82)\end{array}$ \\
\hline $\mathrm{F}$ & $\begin{array}{l}\text { Pregnant Females Giving } \\
\text { Birth }(\mathrm{n})=\mathrm{B}-\mathrm{E}\end{array}$ & $50(60-10)$ & $70(82-12)$ \\
\hline G & $\begin{array}{l}\text { Live Born Offspring's }(\mathrm{n})=\mathrm{F} \\
\mathrm{x} \text { D }\end{array}$ & $56(50 \times 1.13)$ & $73(70 \times(1.04)$ \\
\hline $\mathrm{H}$ & $\begin{array}{l}\text { Pre-mature Offspring } \\
\text { Mortality (n) } \\
=\text { ExpOMP (Fentie et al., } 2016 \\
\& C S A 2016 / 17) \times G\end{array}$ & $\begin{array}{c}10 \\
(18.8 \% \times 57)\end{array}$ & $\begin{array}{c}14 \\
(18.8 \% \times 73)\end{array}$ \\
\hline $\mathrm{H}$ & $\begin{array}{l}\text { Viable Offspring's Wasted (n) } \\
=\mathrm{G}-\mathrm{H}\end{array}$ & $46(57-11)$ & $59(73-14)$ \\
\hline I & $\begin{array}{l}\text { Average NMRV (Birr/Animal) } \\
\text { (Shapiro et al., 2017) }\end{array}$ & 267.3 & 223.0 \\
\hline $\mathrm{Ja}$ & $\begin{array}{l}\text { NEL (Birr for total females } \\
\text { examined) = I x H }\end{array}$ & $\begin{array}{c}12,243.6 \\
(267.3 \times 46)\end{array}$ & $\begin{array}{c}12,172.2 \\
(223 \times 59)\end{array}$ \\
\hline $\mathrm{Jb}$ & NEL $($ USD) $=$ Ja/ 38.82 & $315.4(12,179.7 / 38.82)$ & $\begin{array}{l}313.55(13,128.9 / \\
38.82)\end{array}$ \\
\hline $\mathrm{Ka}$ & $\begin{array}{l}\text { NER (Birr per } 1 \text { mature } \\
\text { female) = Ja/ A }\end{array}$ & $66.9(12,179.7 / 183)$ & $65.5(13,128.9 / 201)$ \\
\hline $\mathrm{Kb}$ & $N E R(U S D)=J b / A$ & $1.72(315.4 / 183)$ & $1 / 69(313.55 / 201)$ \\
\hline
\end{tabular}




\section{Discussion}

Postmortem gross reproductive examination of 384 female small ruminants at Addis Ababa abattoir revealed substantial prevalence of pregnancy (37\%) and fetal wastage (39.8 \%) accompanied by occasional pyometra (1.6\%) and imminent abortion (1\%). Majority of female small ruminants slaughtered at the abattoir seem to have normal breeding potential as evidenced by rare genital disorders and frequent pregnancy postmortem. In sub-Saharan Africa, pregnant livestock slaughter has been linked to rising unmet domestic demands for meat, farmer economic and husbandry limitations, weak slaughter regulation and other (biological, social and climatic etc.) influences (Abassa, 1995; Tizhe et al., 2010; Atawalna et al., 2013; Mshelia et al., 2015). Ethiopian statistics indicate 1.92 million female small ruminants were slaughtered for domestic consumption in 2017 (CSA, 2017). Previous figure shows a jump of 0.66 million from values a decade back (CSA, 2007) and this was probably driven by growing unmet domestic meat demands (Shapiro et al., 2017). Majority of local small ruminant slaughters occur in unregulated backyards (Legese and Fadiga, 2014) and low-capacity public abattoirs (Mummed and Webb, 2015). Such scenarios reflect risks of broader indiscriminate pregnant livestock slaughter in the country. By contrast, pregnant maternal slaughter in developed regions was often tied to economic reasons like harvesting medicinal pregnancy hormones, salvaging expenses when meat prices drop, etc (Fayemi and Muchenje, 2013).

Pregnant small ruminants slaughtered at Addis Ababa abattoir were between 42 and 109 days of gestation. Majority of pregnant animals were in $2^{\text {nd }}$ trimester $(69 \%)$ followed by $1^{\text {st }}(22.5 \%)$ and $3^{\text {rd }}(8.5 \%)$ trimester stages in decreasing order $(p<0.05)$. Producers appear to verify small ruminant pregnancy by inspecting for gross physical changes like abdominal and mammary enlargement apparent after 100 (often later) days i.e., small percentage of potential pregnant animals targeted for meat. Absence of formidable pregnant small ruminant screening and/ or slaughter regulation at abattoir level appears to allow considerable risk of fetal wastage. If done by experienced examiner, abdominal palpation/ ballottement for fetal masses can detect small ruminant pregnancy after 70 (preferably 90) days post service. Using real time B mode ultrasonography, it is possible to identify pregnancies as early as 27 (rectal probe) to 40 (trans-abdominal probes) day post-service. The technique offers further benefits of determining litter size as well as age, sex and viability of fetuses. Plasma or milk progesterone levels of $2.5-4 \mathrm{ng} / \mathrm{ml} 18-23$ days post- 
breeding offers a reliable (80-84 \%) indirect indicator of pregnancy whereas $1 \mathrm{ng} / \mathrm{ml}$ and lower levels at same intervals confirms (100\%) absence of pregnancy (Noakes et al., 2001; Tamassia, 2007; Ptaszynska, 2009).

Postmortem small ruminant pregnancy was currently higher in January (42.8 \%) compared to December (31.1\%). Based on pregnancy detection month and stage, conceptions peaked during October and November months. January represents middle of long dry season wherein pasture feed resources is declining as well as a period of high meat demand by Orthodox Christians before stating two months long fast (Seleshe et al., 2014). Small ruminant producers trying to avert risks posed by escalating feed scarcity and attracted by favorable prices may unknowingly sell grossly unapparent pregnant stocks for meat in later month. Conception dates of corresponding gestations coincide with relatively good pasture feed availability at end of major rains reflecting nutrition modulated seasonal fertility fluctuations. Tropical small ruminant flocks exhibit limited breeding seasonality (Ptaszynska, 2009; Petrovic et al., 2012) evidenced by fertile mating peaks around the major and/ or short rains both in Ethiopia and sub-Saharan Africa (Otte and Chilonda, 2002; Abebe, 2008). Brief duration of current abattoir study, could not give full picture of seasonal breeding trends for concerned national small ruminant flocks. A related drawback was inability to evaluate seasonal reproductive trends according to verified geographical origin of study animals.

Currently, abattoir pregnancy and fetal prevalence in ewes $(40.8 \%$ and 42.8 $\%)$ and doe (32.8 \% and $37.2 \%)$ were comparable but twining was lower ( $p$ $<0.05)$ in former $(1.5 \%)$ compared to later $(4.4 \%)$ species. The two species showed consistent frequency of different gestation stages $\left(2^{\text {nd }}>1^{\text {st }}>3^{\text {rd }}\right.$ trimesters) and overlapping peak fertile mating periods (October and November). Hence conditions influencing reproductive activity and slaughter fate of doe and ewes appear similar. Previous Ethiopian studies had signaled alarming abattoir pregnancy levels including $71.7 \%$ (24\% twins) in central highland sheep (Mukasa-Mugerwa and Tekelye, 2003) as well as $74.4 \%$ (45.7\% twins) in sheep and $47.6 \%$ (60\% twins) in goats at Asella town (Tamirat et al., 2015). Conversely, a recent undergraduate study at Jigjiga abattoir (Yikeber, 2018 ) reported lower postmortem pregnancy prevalence in goats (22.9 \% (1.8 $\%$ twins) and sheep (31.5 \% (2.7 \% twins)). In parallel with Ethiopian trends, widely varying abattoir small ruminant pregnancy and fetal wastage levels have been reported from other African countries. Main examples include 38.6 to $57.7 \%$ (2.2\% multiple fetuses) in sheep and 40 to $51.8 \%$ (3.5 - $33 \%$ multiple 
fetuses) in goats from Tanzania (Swai et al., 2015; Kashoma and Melkiory, 2017; Kilumbi and Nonga, 2018); 15.7 to $47.7 \%$ (25.1\% multiple fetuses) in sheep and 19 to $59 \%$ (17.3 - $66.3 \%$ multiple fetuses) in goats from Nigeria (Addass et al., 2010; Tizhe et al., 2010; Mshelia et al., 2015; Okorie-Kanu et al., 2018); and $50.6 \%$ (50.4\% multiple fetuses) in sheep and $20.4 \%$ (77.35\% multiple fetuses) in goats from Ghana (Tasiame et al., 2016). Most Ethiopian and African studies had observed higher fetal wastage in $1^{\text {st }}$ and/ or $2^{\text {nd }}$ trimesters suggesting drawbacks of gross physical pregnancy screening approaches adopted across the region.

Discrepancy of abattoir fetal wastage across and within geographic regions has been attributed to variable climatic, husbandry and genetic influences on fertility (Addass et al., 2010; Tizhe et al., 2010; Fayemi and Muchenje, 2013). Ethiopian studies reflect higher risk of pregnant slaughter in sheep but higher frequency of twining in goats with effect of evening out total species fetal wastage volumes. Fetal wastage in both species also tended to be higher in highland compared to lowland abattoirs. Ethiopian highland sheep tend to have short heavy body frame with coarse wavy wool that conceals abdomen whereas local goats often show lean body frames with short smooth hair coats (FARM Africa, 1996; Awgichew and Abegaz, 2008). Such differences could render gross detection of late pregnancies more difficult in ewes compared to doe resulting in parallel pregnant slaughter discrepancies. Greater pastoralist milk supply function of goats (Awgichew and Abegaz, 2008; Legesse and Fadiga, 2014) could further discourage slaughter of goats with suspected pregnancy. Relatively better pasture and crop byproduct availability in highland compared to lowland areas (Gizaw et al., 2010; Sheriff and Alemayehu, 2018) could reflect fertility effects corresponding to abattoir pregnancy variations. Twining rate of indigenous sheep and goat's shows wide variability $(2-51 \%)$ reflecting genetic and nutritional influences on ovulation rates (Sheriff and Alemayehu, 2018). Broader feeding range of goats compared to sheep may allow higher ovulation rates in former species under pasture deficient conditions. Further, Somali and Borana pastoralists were suggested to deliberately cull twin bearing doe for slaughter so as to improve kid survival and family milk supply (FARM-Africa, 1996).

Economic cost of abattoir small ruminant fetal wastage was currently estimated employing species-specific approach that accounted for average expected pregnancy and offspring losses as well as net financial values of national flocks. Gross fetal wastage levels observed at Addis Ababa abattoir were pro- 
jected to result in net loss of 105 potential viable offspring's (46 goat and 59 sheep) amounting to NEL 313.55 USD in sheep and 315.4 USD in goats. Later estimates reflect NER of around 1.7 USD attributable to fetal wastage for each mature doe and ewe slaughtered at the abattoir. If $50 \%$ of the 36,000 sheep and 18,000 goats reported to be annually slaughtered at the abattoir (Assefa et al., 2017) were in active breeding state, current NER estimates would result in NEL of 45,900 USD per year. If same NER level was extended to half of annual domestic female goat $(875,406)$ and sheep $(1,049,052)$ slaughters (CSA, 2017), Ethiopia stands to lose around 3.3 million USD due to abattoir fetal wastage. Previous studies had reported higher abattoir small ruminant fetal wastage related to annual economic losses of 158,560.0 USD in Ethiopia (Tamirat et al., 2015) and 464,940.0 - 774,900.0 USD in Tanzania (Kashoma and Melkiory, 2017). Larger annual female slaughter volumes; lower expected pregnancy (14 \%) and neonatal (19\%) loss risks; and higher gross small ruminant market values used towards later projections could explain corresponding inflated projections. Meanwhile, annual economic losses calculated based on gross market values of small ruminant newborns (15 - 20 USD) was estimated between 228, 240.0 and 380,400.0 USD at two Tanzanian abattoirs (Kilumbi and Nonga, 2018) and around 46,480 USD in Nigerian goats (Okorie-Kanu et al., 2018). Apart from considering larger annual female slaughter volumes and net animal financial values, later studies ignored risks of heavy pre-weaning mortality expected under tropical small ruminant farming systems (Abassa, 1995; Otte and Chilonda, 2002; Fentie et al., 2016).

Causes of reproductive failure (infertility) in small ruminants are diverse involving failure to mate; failure to conceive; embryo or fetal loss; and neonatal mortality (Ptaszynska, 2009). Research on epidemiology of small ruminant infertility is patchy in Ethiopia (Abebe, 2008). This study noted higher prevalence of imminent abortion (2.2\%) and pyometra (2.7 \%) in goats as compared to only $0.5 \%$ pyometra in ewes. Abortion is a major cause of small ruminant infertility associated to specific or non-specific genital infections, environmental stress and/ or maternal factors (Ptaszynska, 2009; Pugh, 2016). Previous small ruminant abortion prevalence estimates in Ethiopia varied from 2.4 to $45.4 \%$ (Abassa, 1995; Fentie et al., 2016). The etiological and predisposing factors behind such discrepancy are not well known. Non specific genital infections have been given limited attention in small ruminants compared to larger livestock. Yet, predisposing risk factors such as abortion, genital prolapse, dystocia and placenta retention are common in small ruminant suggesting potential importance of non-specific genital infections in these species. 


\section{Conclusions}

Despite limited temporal coverage and sample size, this study tried to offer useful insights on epidemiology and financial impacts of pregnant doe and ewe slaughtered (fetal wastage) at Addis Ababa abattoir. Regular slaughter of mature female animals coupled with lack of robust ante-mortem pregnancy screening system appears to contribute to substantial fetal wastage in physically inconspicuous gestational stages. This trend could undermine sustainable livestock meat productivity and consumption. Hence, further studies are needed to deepen knowledge on epidemiology and impacts of abattoir pregnancy/ fetal wastage at broader scale including other food animal species. Responsible bodies need to pay attention to this wasteful practice and enact proper regulations by evaluating feasibility of accurate ante-mortem pregnancy screening primarily by ultrasound scanning systems.

\section{Conflict of interests}

The authors have not declared any competing of interests

\section{References}

Abassa, K. P., 1995. ILCA working document - Reproductive losses in small ruminants in Sub-Saharan Africa: A review. International Livestock Center for Africa (ILCA), Addis Ababa, Ethiopia. Pp.1-169.

Abebe, G., 2008. Reproduction in Sheep and Goat. In: Yami, A. and Merkel, R.C. (Eds.), Sheep and Goat Production Handbook for Ethiopia. Ethiopia Sheep and Goat Productivity Improvement Program (ESGPIP), Brana Printing Press, Addis Ababa, Ethiopia, Pp. 60-79.

Addass, P. A., Midau, A., Milka, M. and Tizhe, M. A., 2010. Assessment of Abattoir foetal wastage of cattle, sheep and goat in Mubi main Abattoir Adamawa State. Nigeria. World J. Agric. Sci., 6 (2), 132-137.

Assefa, D., Gezahegn, E., Abera, B., Eticha, E., Lemma, D. and Hailemariam, T., 2017. Major Cause of Organ and Carcass Condemnation in Apparently Healthy Small Ruminant Slaughtered at Addis Ababa Abattoir Enterprise, Ethiopia. J. Vet. Sci. Technol., 8, 1-7.

Atawalna, J., Emikpe, B. O., Shaibu, E., Mensah, A., Eyarefe, O. D. and Folitse, R. D., 2013. Prevalence of Fetal Wastage in Cattle Slaughtered at the Kumasi Abattoir, Kumasi, Ghana. Global Vet., 11 (4), 399-402. 
Awgichew, K. and Abegaz, S., 2008. Breeds of sheep and goats. In: Yami, A. and. Merkel, R.C. (Eds.), Sheep and Goat Production Handbook for Ethiopia. Ethiopia Sheep and Goat Productivity Improvement Program (ESGPIP), Brana Printing Press, Addis Ababa, Ethiopia, Pp. 5-26.

Beshada, G., 2012. Optimizing logistic chain of animal transport and meat distribution: studies on livestock markets and abattoirs in Addis Ababa city. M.Sc. Thesis, Addis Ababa Institute of Technology School of Graduate Studies, Addis Ababa University, Addis Ababa, Ethiopia.

CSA (Central Statistical Agency), 2007. Livestock and Livestock Characteristics, Agricultural Sample Survey, Addis Ababa, Ethiopia. Statistical Bulletin, 2 (417). Pp. 13-26.

CSA (Central Statistical Agency), 2017. Livestock and Livestock Characteristics, Agricultural Sample Survey, Addis Ababa, Ethiopia. Statistical Bulletin, 2(583). Pp. 13-26.

ESGPIP (Ethiopia Sheep and Goat Productivity Improvement Program). Body condition scoring of sheep and goat, Technical Bulletin No. 8 http://www.esgpip.org/ PDF/Technical\%20bulletin\%20No8.html

Eshetie, T., Hussien, K., Teshome, T. and Mekonnen, A., 2018. Meat production, consumption and marketing tradeoffs and potentials in Ethiopia and its effect on GDP growth: a review. J. Nutr. Hlth. Food Eng., 8 (3), 228-233.

FARM Africa, 1996. Goat Types of Ethiopia and Eritrea. Physical description and management systems. Published jointly by FARM-Africa, London, UK and International Livestock Research Institute (ILRI), Nairobi, Kenya. Pp. 1-76.

Fayemi, P. O. and Muchenje, V., 2013. Maternal slaughter at abattoirs: history, causes, cases and the meat industry. Springerplus, 2, 125.

Fentie, T., Temesgen, W., Melaku, A., Getachew, A., Tesfaye, S., Fufa, F., et al., 2016. Assessment of young stock mortality in major livestock production systems of Ethiopia: Revised Research Report. Feed the Future - Research Award, United States Agency for International Development (USAID), Pp. 1-43.

Gizaw, S., Tegegne, A., Gebremedhin, B. and Hoekstra, D., 2010. Sheep and goat production and marketing systems in Ethiopia: Characteristics and strategies for improvement. Improving Productivity and Market Success (IPMS) of Ethiopian Farmers Project Working Paper 23, International Livestock Research Institute (ILRI), Nairobi, Kenya. Pp. 1-58.

Hussein, A. A., 2008. Determination of first pregnancy and foetal measurements in Egyptian Baladi goats (Capra hircus). Vet. Ital., 44 (2), 429-437. 
Kashoma, I. P. and Melkiory, G. U., 2017. Foetal wastage and prevalence of ovarian disorders in goats slaughtered at Dodoma Municipal abattoir, Tanzania. In: Proceedings, $34^{\text {th }}$ Scientific Conference of the Tanzania Veterinary Association (TVA), Arusha, Tanzania. Pp. 123-128.

Kilumbi, L. A. and Nonga, H. E., 2018. Magnitude of foetal wastage and the monetary losses in sheep and goats slaughtered in Morogoro selected slaughter facilities. In: Proceedings, $35^{\text {th }}$ Scientific Conference of the. Tanzania Veterinary Association (TVA), Morogoro, Tanzania. Pp. 225-229.

Legese, G. and Fadiga, M., 2014. Small Ruminant Value Chain Development in Ethiopia: Project Report - Situation Analysis and Trends. International Center for Agricultural Research in the Dry Areas (ICARDA)/ International Livestock Research Institute (ILRI), Nairobi, Kenya. Pp. 1-85.

Ministry of Agriculture (MoA), 1993. Proclamations and Regulations of Veterinary Services. Animals, Animal Products and By-products Inspection and Quarantine Regulation No. of 19 Meat Inspection Regulation Section 2 Ante-mortem Inspection (Article 10.3.). November1993 Addis Ababa, Ethiopia. Pp. 5-6.

Mshelia, G. D., Maina, V. A. and Aminu, M. D., 2015. Foetometrics and Economic Impact Analysis of Reproductive Wastages in Ruminant Species Slaughtered in North-Eastern Nigeria. J. Anim. Pro. Adv., 5 (4), 645-653.

Mukasa-Mugerwa, E. and Tekelye, B., 2003. The reproductive performance of Ethiopian Highland sheep. Ani. Repro. Sci., 17 (1-2), 95-102.

Mummad, Y. Y. and Webb, E. C., 2015. Operation, Facilities and management in public and private abattoirs in Ethiopia. African J. Agri. Res., 10, 623-630.

Noakes, D. E., Parkinson, T. J. and England, G. C.W., 2001. Pregnancy and its diagnosis. In: Veterinary Reproduction and Obstetrics, $8^{\text {th }}$ edition, Saunders Elsevier, UK. Pp. 106-110.

Okorie-kanu, O. J., Ezenduka, E.V., Okorie-kanu, C. O., Anyaoha, C. O., Attah, C. A., Ejiofor, T. E. and Onwumere-Idolor, S. O., 2018. Slaughter of pregnant goats for meat at Nsukka slaughterhouse and its economic implications: A public health concern, Vet. World, 11 (8), 1139-1144.

Otte, M. J. and Chilonda, P., 2002.Cattle and small ruminant production systems in sub-Saharan Africa-A systematic review. Livestock information sector analysis and policy branch, Food and Agriculture Organization (FAO) of the United Nations, Rome, Italy. Pp. 1-98.

Petrovic, M. P., Caro Petrovic, V., Ruzic Muslic, D., Maksimovic, N., Ilic, Z., Milosevic, B. and Stojkovic, J., 2012. Some important factors affecting fertility in sheep. Biotechnol. Anim. Husb., 28 (3), 517-528.

Ethiop. Vet. J., 2021, 25 (1), 110-127 
Ptaszynska, M., 2009. Compendium of Animal Reproduction, $10^{\text {th }}$ edition, Intervet, Shering-Plough Animal Health, Intervet International. Pp. 257-319.

Pugh, D. G., 2016. Fetal loss in small ruminants. In: Proceedings, Annual Conference of the Society for Theriogenology. Asheville, NC, USA. www.ivis.org.

Seleshe, S., Cheorun, Jo. and Lee, M., 2014. Meat Consumption Culture in Ethiopia. Korean J. Food Sci. An., 34 (1), 7-13.

Shapiro, B. I., Gebru, G., Desta, S., Negassa, A., Nigussie, K., Aboset, G., et al., 2017. Ethiopia livestock sector analysis- Project Report. International Livestock Research Institute (ILRI). Nairobi, Kenya. Pp.1-103.

Sheriff, O. and Alemayehu, K., 2018. Small ruminant production systems and breeding programs in Ethiopia: achievements, challenges and lessons learned: A Review. Online J. Anim. Feed Res., 8 (3), 59-73.

Sivachelvan, M. N., Ali, M. G. and Chibuzo, G. A., 1996. Foetal age estimation in sheep and goats. Small Rumin. Res., 19, 69-76.

Swai, E. S., Ayubu, H. and Mhina, B. S., 2015. Prevalence of foetal wastage in sheep and goats slaughtered at Tanga city abattoir, Tanga, Tanzania. Livest. Res. Rural. Dev., 27, 213.

Tamassia, M., 2007. Pregnancy Diagnosis in the Ewe. In: Schatten, H. and Constantinescu, G. M. (Eds.), Comparative Reproductive Biology. Blackwell Publishing Ltd., Oxford, UK. Pp. 337-342.

Tamirat, C., Wakayo, B. U., Mohammed, O. and Dewo, T. F., 2015. Small Ruminant Fetal Wastage at Asella Abattoir in Central Ethiopia; Reflection on Potential Country Level Implications. Int. J. Livest. Res., 5, 55-61.

Tasiame, W., Emikpe, B., Folitse, R. D., Fofie, C. O., Johnson, S., Burimuah, V., et al., 2016. Foetal Wastage in Sheep and Goats at the Kumasi Abattoir in Ghana: A Cross Sectional Study. Arch. Bas. App. Med., 4, 95-98.

Tizhe, M. A., Kubkomawa, H. I., Waba, Y. E. and Addass, P. A., 2010. Foetal wastage in ruminants and sustainable livestock industry in Nigeria. J. Agric. Vet., 2, 72-80

Thrustfield, M., 2005. Veterinary Epidemiology, $3^{\text {rd }}$ edition, Blackwell Publishing, UK. Pp. 228-246/ 436-462.

Yikeber, W., 2017. Abattoir and clinical investigations on small ruminant reproductive disorders in Jigjiga, Ethiopia, DVM Thesis, Jigjiga University, College of Veterinary Medicine, Jigjiga, Ethiopia. 